\title{
Deep infiltrating endometriosis affecting the urinary tract-surgical treatment and fertility outcomes in 2004-2013
}

\author{
Liisu Saavalainen $^{1}$ - Oskari Heikinheimo ${ }^{1}$ - Aila Tiitinen ${ }^{1}$ P Päivi Härkki ${ }^{1}$
}

Received: 25 November 2015 / Accepted: 18 May 2016/Published online: 26 May 2016

(C) Springer-Verlag Berlin Heidelberg 2016

\begin{abstract}
Urinary tract endometriosis (UTE) is a rare form of deep infiltrating endometriosis. We studied the operative treatment of UTE and evaluated postoperative recurrences and fertility outcomes. This is a retrospective cohort study of 53 women who underwent operative treatment for UTE in 2004 2013 at Helsinki University Hospital, and were followed-up until the end of 2014. The data were gathered from the hospital's electronic database. The main outcome measures were complications, reoperations, postoperative pregnancies, and deliveries. Preoperative diagnosis was accurate in $72 \%$ with bladder endometriosis and in $93 \%$ with ureteral disease. Thirty-one $(58 \%)$ of the 53 operations were performed via laparoscopy. Postoperative complications requiring reintervention occurred in five cases $(9 \%)$. Five reoperations were performed in four cases due to endometriosis recurrence, only two due to recurrence of UTE (4\%). Twenty-eight women wished for pregnancy; 18 (64\%) of them conceived. Infertility treatment was needed in $20(71 \%)$ cases. Twelve $(75 \%)$ women delivered via cesarean section; intraoperative difficulties occurred in ten $(83 \%)$. The complication rate with UTE operations is acceptable and recurrences are rare. Infertility is common, but $57 \%$ of those who wished for a child succeeded. A majority of the deliveries involved unplanned and complicated cesarean section.
\end{abstract}

Keywords Endometriosis $\cdot$ Bladder $\cdot$ Fertility $\cdot$ Ureter . Urinary tract

Päivi Härkki

paivi.harkki@hus.fi

1 Department of Obstetrics and Gynecology, University of Helsinki and Helsinki University Hospital, Sofianlehdonkatu 5, PO Box 610, FI-00029 HUS Helsinki, Finland

\section{Background}

Urinary tract endometriosis (UTE) is a form of deep infiltrating endometriosis (DIE) affecting $0.3-12 \%$ of all women suffering from endometriosis $[1,2]$ and $14-20 \%$ of all DIE patients [3]. According to the latest article, $52 \%$ of DIE patients may suffer from UTE [3]. Of the various forms of UTE, bladder endometriosis is the most common ( $85 \%$ ), followed by that of the ureter (9\%), kidney (4\%), and urethra (2\%) [1].

Regarding symptomatology, $70 \%$ of patients with bladder endometriosis suffer from urinary frequency, urgency, and dysuria, and 20-35\% from hematuria. When endometriosis involves the ureters, there often are no symptoms, which might lead to silent loss of renal function [2]. The risk of ureteral endometriosis increases if a rectovaginal nodule is larger than $3 \mathrm{~cm} \mathrm{[3-5].} \mathrm{Thus,} \mathrm{urinary} \mathrm{tract} \mathrm{ultrasonography,}$ urography, or magnetic resonance imaging (MRI) is recommended when planning surgery for DIE $[6,7]$.

The treatment of choice for severe DIE not responding to medication is surgery, i.e., complete resection of all endometriotic lesions including possible bladder, ureteral, and bowel lesions. Surgical treatment results in good pain relief for a long time [8] and $90 \%$ of patients are satisfied [9]. Surgery is the first option in cases of UTE-related hydronephrosis. Moreover, it has been suggested that the recurrence rate of bladder endometriosis is lower than that seen in connection with other forms of endometriosis [10].

However, unlike pelvic pain, there is no consensus concerning the first-line treatment of infertility (surgery vs. assisted reproduction techniques (ART)) in DIE patients. According to the ESHRE guidelines, there is not enough evidence to propose surgery before ART [11]. In addition, there are conflicting results on impact of endometriosis on infertility: presence of endometrioma may [12] or may not [13, 14] reduce ovarian reserve and even the presence of DIE may 
have an impact on ovarian function $[15,16]$. On the other hand, surgery of ovarian endometrioma may [17] or may not [18] have a negative impact on ovarian reserve, and surgery of DIE may $[19,20]$ or may not improve fertility [21, 22]. Nevertheless, these operations carry a high risk of complications [9]. Even though fertility is often unaffected by such complications, pregnancy rates are lower after bowel versus urinary tract complications [23]. After repeated operations, fertility is further diminished $[24,25]$. On the other hand, delaying surgery may lead to prolonged painful complaints during ART and eventually to more difficult surgery [26]. Finally, infertility is multifactorial in endometriosis patients and the choice of treatment is individual.

The aims of the present study were to evaluate the outcome of operative treatment of UTE, to study factors affecting postoperative fertility, and to analyze the course of postoperative pregnancies.

\section{Methods}

During a 10-year period from January 2004 to December 2013, a total of 53 women underwent surgical treatment for UTE at our department. The department is a tertiary referral hospital and also one of the referral centers for patients with severe endometriosis. During the study period, we also operated altogether 400 women with DIE of the rectovaginal septum; 182 of those involved colorectal resection and $70 \%$ of the bowel procedures were performed laparoscopically. Patient records in the hospital district of Helsinki and Uusimaa (HUS) are electronic, and therefore all operations, complications, and reoperations can be identified and the data retrieved. The patients were identified on the basis of diagnosis and specific surgical codes. In this study, we included all bladder resections for endometriosis with or without concomitant procedures and all ureteroneocystostomies (UNC) for severe ureteral endometriosis. Extrinsic ureteral endometriotic nodules were completely resected around the ureters without UNC among six patients in connection with operation of bladder endometriosis. Unfortunately, we are missing the most of those patients with ureterolysis associated with DIE in the rectovaginal septum not connected with bladder endometriosis as a result of a lack of specific surgical code. Thus, these patients are not included as a separate group in the present study.

Before initiation of this study, Institutional Review Board approval was obtained (21.3.2013). The ethics committee of the Hospital District of Helsinki and Uusimaa approved the study protocol (28/13/03/03/2013).

\section{Operative techniques}

The patients were often approached by a multidisciplinary team. Gynecologists were experienced in advanced laparoscopic surgery with the aid of one assistant. All bladder resections were performed by a gynecologist. All UNCs were performed together with a urologist. A gastrointestinal surgeon was involved if bowel endometriosis was to be treated. One gynecologist (P.H.) performed 43 (78\%) of all the operations. In 33 (62\%) cases, either a urologist (in 23 operations) or/and a gastrointestinal surgeon (in 22 operations) was present. The same urologist was present in 11 and the same gastrointestinal surgeon in 14 of all the operations.

Partial cystectomy was performed either via laparoscopy $(n=31)$ or laparotomy $(n=12)$. Bladder nodules were separated from the anterior wall of the uterus and complete excision of these nodules was carried out. The bladder was sutured in most cases in a single layer with continuous resorbable sutures and a bladder catheter was left in place for 10 days postoperatively. Ureteral stents were used only in cases of ureteral proximity. Full-thickness bladder resection was carried out except for two cases where the nodule was mobilized and excised without opening the mucosal layer of the bladder wall.

To perform ureteral shaving in association with bladder operation, the ureter was freed from all fibrotic tissue and the endometriotic nodule was removed laparoscopically.

Ureteral stenting was always carried out either via cystoscopy or cystostomy during UNC procedures when endometriosis involved the ureters. All cases of ureteral reimplantation with UNC ( $n=13)$ were performed via laparotomy with a urologist. Large endometriotic nodules affecting the ureters were excised; the ureter was cut above the nodule and reimplanted into the bladder. Ureteral stents were left in place for 4 to 6 weeks and bladder catheters for 10 days.

Prophylactic antibiotics were given to all-a combination of cefuroxime $(1.5 / \mathrm{g})$ and metronidazole $(0.5 / \mathrm{g})$ intravenously in $34(64 \%)$ cases and cefuroxime $(1.5 / \mathrm{g})$ intravenously in 15 (28\%). Peroral antibiotics were continued as long as a catheter was in a bladder or ureter. Low-molecular-weight heparin was used after 33 (62\%) operations. Patients were discharged with a bladder catheter and visited hospital for its removal after routine cystography.

\section{Follow-up and data collection}

After surgery, the women were followed-up with a scheduled visit at 1-2 months postoperatively. Symptoms of pain, urinary and bowel function were inquired at the time of the visit without validated questionnaires or urodynamic examinations. Data concerning demographic characteristics, as well as pre-, per-, and postoperative data were collected retrospectively from the electronic patient files. The follow-up period was until the end of 2014.

Complications were graded according to the ClavienDindo classification system as follows: I, minor complications not requiring medical or surgical intervention; II, 
complications requiring pharmacological treatment or blood transfusion; III, complications requiring re-intervention; IV, life-threatening complications, and V, death [27].

Recurrences were defined as cases requiring a new operation. We also assessed the factors associated with postoperative fertility among women younger than 43 years of age at the time of operation. All pregnancies and deliveries, but not biochemical pregnancies, were analyzed.

\section{Statistical analysis}

Statistical analysis was performed by using the Statistical Package for the Social Sciences (SPSS) version 21.0 for Windows. The chi-square test and Fisher's exact two-sided test were used as necessary. Means were compared by using Student's $t$ test. Differences were considered statistically significant if $p<0.05$.

\section{Findings}

\section{Demographics and preoperative data}

During the study period, 53 women underwent surgery for UTE. The patients were referred to the clinic because of a known history of DIE or symptoms typical of UTE such as dysuria, urinary urgency, or hematuria, or because of radiological findings such as hydronephrosis. Infertility was not the main indication for operative management in any case.

The characteristics of the study patients are summarized in Table 1. Altogether, 31 (58 \%) women had preoperative urinary symptoms, with macroscopic hematuria in seven $(13 \%)$ patients. Every patient was examined by means of vaginal

Table 1 Patients characteristics and their preoperative data $(n=53)$

\begin{tabular}{llc}
\hline Variable & Number & Percent \\
\hline Age (years (mean, SD)) & 35.0 & 4.4 \\
BMI (kg/m² (mean, SD)) & 23.1 & 3.7 \\
Smoking & 10 & 19 \\
History of previous pregnancy & 11 & 21 \\
Nulliparous & 47 & 89 \\
History of infertility & 28 & 53 \\
Previous operative treatment due to endometriosis & 24 & 45 \\
Preoperative hormonal treatment & 23 & 43 \\
Preoperative symptoms & & \\
$\quad$ Dysmenorrhea & 48 & 91 \\
$\quad$ Dysuria, pollakisuria, and/or hematuria & 31 & 58 \\
Dyschezia and/or hematemesis & 20 & 38 \\
Dyspareunia & 21 & 40 \\
\hline
\end{tabular}

Data are shown as $n(\%)$ unless stated otherwise. $(n=53)$ gynecological ultrasonography. Preoperatively, magnetic resonance imaging (MRI) was performed in $33(62 \%)$ patients and computed tomography (CT) in eight (15\%). In $13(25 \%)$ cases, there were no preoperative imaging examinations concerning the ureters or kidneys. Altogether, 13 cystoscopies were performed preoperatively. Preoperative diagnosis was accurate in $31(72 \%)$ cases concerning bladder endometriosis and in $13(93 \%)$ cases concerning ureteral disease.

The patients were divided into three groups as follows: Group A: patients with isolated bladder endometriosis excluding DIE elsewhere $(n=8)$ (procedures performed: isolated partial cystectomy or shaving (two patients)). Group B: bladder endometriosis associated with other types of endometriosis but no intrinsic ureteral lesions $(n=31)$ (procedures: partial cystectomy with concomitant procedures excluding UNC). Group $\mathrm{C}$ : severe ureteral endometriosis associated with other types of endometriosis $(n=14)$ (procedures: UNC with concomitant procedures including partial cystectomy (three patients) and nephrectomy (one patient)). The diagnosis of endometriosis was confirmed by histology in each case.

\section{Operative data}

Thirty-one $(58 \%)$ of the 53 operations were performed via laparoscopy. The mean $( \pm \mathrm{SD})$ operative time in laparoscopic procedures was $146 \pm 61 \mathrm{~min}$ and blood loss was $73 \pm 122 \mathrm{ml}$. Corresponding figures were $225 \pm 81 \mathrm{~min}$ and $1567 \pm 1107 \mathrm{ml}$ in procedures performed via laparotomy. As the difficulty of the operations increased from Group A to Group C, the proportion of laparotomies as well as the length of operating time increased (Table 2). The length of sick leave was $26 \pm 16$ days vs. $58 \pm 67$ days in procedures performed via laparoscopy vs. laparotomy, respectively.

There were a total of 170 concomitant procedures, which varied from superficial electrocoagulation to nephrectomy (Table 3). The mean number of concomitant procedures in the operations performed via laparoscopy was 2.5 and 4.1 in those performed via laparotomy.

The bladder operations were mostly partial cystectomies ( $n=41$, groups A, B, and C), and shaving of the endometriotic nodule was performed twice (group A). Seventy-two percent of them were operated upon via laparoscopy; laparotomy was chosen in connection with several DIE lesions. All cases of isolated bladder endometriosis (group A) and concomitant six cases of ureteral shavings were operated laparoscopically (group B). The median size of the bladder nodules was $3 \mathrm{~cm}$ (range $2-4 \mathrm{~cm}$ ) and their locations were in the bladder dome in $17(40 \%)$, the posterior wall in $24(56 \%)$, and the trigone in two $(5 \%)$ of the cases. 
Table 2 Perioperative and postoperative data

\begin{tabular}{|c|c|c|c|c|}
\hline Variables & Group A $(n=8)$ & Group B $(n=31)$ & Group C $(n=14)$ & Total $(n=53)$ \\
\hline Laparoscopy & $8(100)$ & $23(74)$ & $0(0)$ & $31(58)$ \\
\hline Three or more concomitant procedures & $0(0)$ & $10(32)$ & $10(71)$ & $20(38)$ \\
\hline Operation time (min, SD) & $123(41)$ & $164(63)$ & $249(89)$ & $180(80)$ \\
\hline Blood loss (ml, SD) & $88(170)$ & $465(853)$ & $1773(1094)$ & $734(1048)$ \\
\hline Hospital stay (days, SD) & $2.3(1.0)$ & $3.9(2.3)$ & $8.5(5.7)$ & $4.9(4.1)$ \\
\hline Women who wished for a child & $6(75)$ & $13(42)$ & $9(64)$ & $28(53)$ \\
\hline Women treated with ART & $3(50)$ & $9(69)$ & $8(89)$ & $20(71)$ \\
\hline Women who conceived & $4(67)$ & $8(62)$ & $6(67)$ & $18(64)$ \\
\hline Conceived spontaneously & $1(17)$ & $4(31)$ & $1(11)$ & $6(21)$ \\
\hline Women who delivered & $3(50)$ & $8(62)$ & $5(56)$ & $16(57)$ \\
\hline
\end{tabular}

Data are shown as $n(\%)$ unless stated otherwise

Group A: isolated partial cystectomy

Group B: partial cystectomy with concomitant procedures excluding UNC

Group C: UNC with concomitant procedures including partial cystectomy

In group $\mathrm{C}, \mathrm{UNC}$ was performed 13 times, twice bilaterally. One concomitant nephrectomy was performed because of a silent kidney with resection of ureteral endometriosis in pelvis. Indications for UNC were moderate hydronephrosis ( $n=5$, one bilateral), severe hydronephrosis with diminished renal function ( $n=6$, one bilateral), persisting large nodule after ureteral shaving done twice $(n=1)$, and silent kidney

Table 3 Concomitant procedures

\begin{tabular}{|c|c|c|}
\hline Variable & Number & Percent \\
\hline $\begin{array}{l}\text { Rectovaginal resection } \\
\text { (other than sacrouterine ligaments only) }\end{array}$ & 32 & 60 \\
\hline Bowel resection & 21 & 40 \\
\hline Vaginal resection & 17 & 32 \\
\hline $\begin{array}{l}\text { Electroresection, puncture, } \\
\text { or enucleation of } \\
\text { endometrioma(s) in the ovaries }\end{array}$ & 17 & 32 \\
\hline Parametrial resection & 16 & 30 \\
\hline Cystoscopy & 13 & 25 \\
\hline $\begin{array}{l}\text { Electrocoagulation of peritoneal } \\
\text { endometriosis }\end{array}$ & 10 & 19 \\
\hline Chromopertubation & 9 & 17 \\
\hline $\begin{array}{l}\text { Salpingo-oophorectomy } \\
\quad \text { (unilateral in } 3, \text { bilateral in } 5 \text { ) }\end{array}$ & 8 & 15 \\
\hline Resection of sacrouterine ligaments ${ }^{\mathrm{a}}$ & 8 & 15 \\
\hline Shaving of ureteral endometriosis & 6 & 11 \\
\hline Hysterectomy & 6 & 11 \\
\hline Protective ileostomy & 4 & 8 \\
\hline Hysteroscopy & 2 & 4 \\
\hline Nephrectomy & 1 & 2 \\
\hline Total & 170 & \\
\hline
\end{tabular}

Data are shown as $n(\%)$

${ }^{\text {a }}$ Counted as a procedure when no rectovaginal resection was carried out $(n=1)$. All UNC operations were performed via laparotomy with the aid of a urologist. UNC was done to the left side eight times, right side three times, and bilaterally twice. Histological examination revealed intrinsic endometriosis of the ureter in one case, whereas in ten cases the disease was extrinsic or the specimen was taken from surrounding tissue not including the ureter.

During all the UTE operations, grade I complications occurred in two (4\%) and grade II complications in $21(40 \%)$ women. None of the complications occurred after operations on isolated bladder endometriosis (group A). In group B, three minor bladder leakages were discovered during routine cystography 10 days after the laparoscopic procedure and therefore bladder catheter was kept for another 2 weeks and removed after normal re-cystography in all three patients. In group $\mathrm{C}$, one patient had urinary leakage from the bladder to the vagina and rectum on the 18th postoperative day after combined bladder and colorectal resection, protective ileostomy, and UNC via laparotomy. Cystography had been normal the day before and bladder catheter had been removed. No fistula was detected during CT urography but leakage came to an end following insertion of a new bladder catheter. After 2 weeks with this catheter, cystography and cystoscopy were normal and leakage vanished. The most common complication was hemorrhage and altogether 16 women in groups $\mathrm{B}$ and $\mathrm{C}$ received blood transfusions after the operations performed via laparotomy.

There were five $(9 \%)$ grade III complications: three reoperations were performed after laparoscopy and two after laparotomy. In group B, one perforation of the ileum occurred after laparoscopic bladder resection with severe bowel adhesions. Ileal resection was performed on the second postoperative day. One UNC was done after ureteral lesion caused by electrocoagulation during 
laparoscopic resection of the bladder, rectum, and rectovaginal nodule. In addition, infection and rupture of bladder sutures occurred on the 14th postoperative day after laparoscopic bladder and rectovaginal nodule resection and re-suturation was performed. In group $\mathrm{C}$, there was one fascial rupture and one postoperative hemorrhage with abscess formation requiring re-laparotomy. There were no life-threatening complications (grade IV), or complications resulting in death (grade V). Postoperative complications requiring re-intervention occurred in $9.7 \%$ of the cases operated via laparoscopy and $9.1 \%$ via laparotomy. Complications are shown in Table 4.

\section{Follow-up data}

Fifty patients (94\%) attended the follow-up visit 1-2 months postoperatively; $100 \%$ in group A, $90 \%$ in group B, and $100 \%$ in group C. Altogether, 12 patients (12/50, $24 \%$ ) had some urinary problems at this time. One patient in group A $(1 / 8,13 \%)$ had transient mild urgency. Eight patients had mild urinary problems in group B $(8 / 28,29 \%$ (four dysuria, one urgency, one incontinence, two lower urinary tract infections)). In addition, one patient in group B had several problems (long-lasting postoperative pain, hematuria, and rehydronephrosis) following shaving of bladder and ureteral endometriosis, and UNC was performed 10 months later.
Finally, two patients in group C $(2 / 14,14 \%)$ had some problems at the follow-up visit. One patient continued to have pyelonephritis from the preoperative to postoperative period. The other patient had persisting pain after UNC which she had had already preoperatively and bladder atony for 4 months requiring self-catheterization; urodynamic studies were normal after 4 months. She was admitted to the pain clinic and eventually underwent hysterectomy 4 years later. These follow-up urinary problems are not included in postoperative complications in Table 4.

The mean overall length of follow-up time was 5.1 years (range 1.1-10.4 years). Two women were lost to follow-up time since they moved to another hospital district; two women were followed only 2.5 and 3 years. Five reoperations were performed among four (8\%) women because of recurrence of endometriosis. Only two of them (4\%) had recurrence of UTE. One patient needed a partial bladder resection 21 months after a shaving operation of the bladder endometriosis. The other patient had undergone previous shaving operation of ureteral endometriosis before an index operation: shaving of the bladder and ureteral nodules, resection of sacrouterine ligament endometriosis, enucleation of bilateral endometrioma, and appendectomy. After 10 months, she had recurrent hydronephrosis and UNC was performed successfully.

Table 4 Complications classified in grades I-V

\begin{tabular}{|c|c|c|c|}
\hline & & Complication $(n)$ & Cure \\
\hline Group A & Grade I-V & - & - \\
\hline \multirow[t]{9}{*}{ Group B } & Grade I & Minor symptoms (postoperative pain) (2) & Hospital stay and follow-up \\
\hline & Grade II & Intraoperative hemorrhage (3), with symptoms of ileus (2) & Blood transfusion, conservative care \\
\hline & & Hydronephrosis (1) & Ureteral catheter \\
\hline & & Postoperative infection (2) & Antibiotics and follow-up \\
\hline & & Minor bladder leakage in cystography (3) & Extended use of bladder catheter \\
\hline & Grade III & Perforation of ileum (1) & Ileal resection \\
\hline & & Leakage from ureter with ileus (1) & Ureteroneocystostomy \\
\hline & & Rupture of bladder suture (1) & Bladder suturing \\
\hline & Grade IV-V & - & - \\
\hline \multirow[t]{6}{*}{ Group C } & Grade I & - & - \\
\hline & Grade II & Intraoperative hemorrhage (7), symptoms of ileus (1), and infection (1) & $\begin{array}{l}\text { Blood transfusion, conservative care, } \\
\text { antibiotics }\end{array}$ \\
\hline & & Leakage from bladder to vagina and rectum, and intraoperative hemorrhage (1) & $\begin{array}{l}\text { Extended use of bladder catheter, } \\
\text { blood transfusion }\end{array}$ \\
\hline & Grade III & Postoperative rupture of fascial sutures, and intraoperative hemorrhage (1) & Fascial resuturing \\
\hline & & Postoperative hemorrhage and abscess (1) & Evacuation of hemorrhage \\
\hline & Grade IV-V & - & - \\
\hline
\end{tabular}

Classification of surgical complications according to Dindo et al. [6]

Group A: isolated partial cystectomy

Group B: partial cystectomy with concomitant procedures excluding UNC

Group C: UNC with concomitant procedures including partial cystectomy and nephrectomy 


\section{Postoperative fertility}

Twenty-eight (53\%) of the 53 women had a wish for pregnancy after the operative treatment of UTE. Two women were to lost to follow-up during the follow-up time. Eighteen women conceived, i.e., $64 \%$ of those who wished for a child (Fig. 1). Analysis of multiple variables revealed no statistically significant difference between the women who conceived vs. those who did not (Table 5).

There were a total of 26 pregnancies, resulting in 19 deliveries (including one twin pregnancy), four miscarriages, and one extrauterine pregnancy. Two pregnancies were ongoing in the third trimester at the end of the follow-up period. Seven (27\%) pregnancies were spontaneous, whereas ART was needed in 19 (73\%) cases, two of them with ovum donation. Altogether, 20 children were born to 16 mothers, and $57 \%$ of those who wished for a child gave birth. The mean $( \pm \mathrm{SD})$ time from UTE operation to delivery of the first child was $2.5 \pm 1.4$ years

The rate of pregnancy complications was high; 10 (63\%) of the 16 first pregnancies required antenatal follow-up or treatment. There were three cases of hemorrhage due to partial placental abruption or total placental previa, three cases of hypertension or preeclampsia, and one case of symptomatic hydronephrosis.

Four of the first deliveries $(25 \%, 4 / 16)$ were vaginal, all among women belonging to Group B. However, 12 (75 \%) were via cesarean section, most (75\%) involving emergency procedures for various reasons. The mean $( \pm \mathrm{SD})$ duration of the cesarean section was $67 \mathrm{~min}( \pm 31 \mathrm{~min})$, and blood loss was $2400 \mathrm{ml}( \pm 2050 \mathrm{ml})$ with no difference between the groups. Similarly, there were intraoperative difficulties in 10 (83\%) cases: 6 cases (i.e., $50 \%$ ) of severe adhesions, four cases of difficulties with extraction of the neonate, 2 cases of bladder laceration, 1 case of uterine atony, and 1 case of difficult placental retrieval. None of the women concerned had had severe complications during their UTE operations. Both women with bladder injuries had undergone partial cystectomy because of bladder endometriosis (group B).

The average weight of the first full-term infants $(n=14)$ was $3.3 \mathrm{~kg}$ (SD $0.48 \mathrm{~kg}$ ), Apgar scores at 5 min were seven or

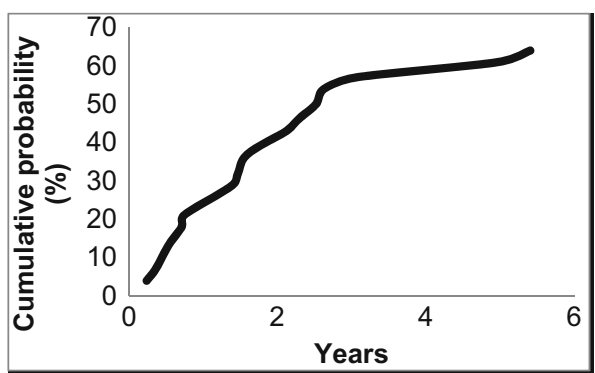

Fig. 1 Number of women who conceived, i.e., $64 \%$ of those who wished for a child more in all cases, and cord blood $\mathrm{pH}$ was on average 7.25 (7.06-7.37). There were three preterm deliveries (19\%) and these neonates were also healthy.

\section{Conclusions}

We found that the UTE operations were usually associated with other DIE lesions making them demanding; isolated bladder and ureteral endometriosis were rare. However, the rate of postoperative complications was acceptable and the recurrence rate was low. The women conceived better than expected according to the results of previous studies concerning DIE other than UTE [28-30], but needed infertility treatment. On the other hand, the pregnancies and deliveries were complicated, and the high rate of complicated cesarean deliveries was particularly worrying.

The patients with UTE were typical endometriosis patients - on average nonsmoking, normal-weight 35-year-old women with a wish for a child and thus no current use of hormonal medication. Nine out of 10 patients suffered from dysmenorrhea and more than half suffered from symptoms suggestive of UTE. As in other studies [7, 10, 31-35], almost half of our patients had a history of previous endometriosis surgery. This might indicate that the delay in reaching the correct diagnosis and getting to the referral center is long.

Urinary tract symptoms occurred in almost three quarters of the patients with bladder endometriosis, and severe pain in nearly half of the patients with ureteral endometriosis. Bladder endometriosis was not suspected preoperatively in nearly a third of the patients; only two of them had urinary tract symptoms and they all suffered from severe DIE. MRI was performed in two thirds of the patients and the preoperative diagnosis was correct in more than $70 \%$ of the cases. Ureteral disease was undiagnosed only once with UNC patients when hydronephrosis was not noticed in MRI [3]. Nowadays, preoperative assessment to localize all DIE lesions is recommended to decide the surgical approach and to plan a multidisciplinary team work. Our preoperative examinations include nowadays thorough ultrasound mapping of the pelvis [36] and MRI to diagnose all DIE lesions and even asymptomatic DIE lesions before renal function is impaired.

Half of all our operations were performed via laparoscopy. A similar rate has been reported in previous studies, in which many concomitant procedures have also been performed [5, 6 , 34] but there are also reports where all or almost all urinary tract operations have been performed laparoscopically [3, 7, 10, 32, 37, 38]. All our isolated bladder resections and associated ureteral shavings were done laparoscopically as in many other series $[10,35,39,40]$ but with increasing amount of concomitant procedures also the proportion of laparotomies increased. Further, in contrast to some other studies [24, 41-43], none of the UNCs were performed via laparoscopy 
Table 5 Characteristics of women wishing to conceive

\begin{tabular}{|c|c|c|c|c|}
\hline Variable & $\begin{array}{l}\text { Women who did } \\
\text { not conceive }(n=10)\end{array}$ & $\begin{array}{l}\text { Women who } \\
\text { conceived }(n=18)\end{array}$ & $p$ value & $\begin{array}{l}\text { Spontaneous } \\
\text { pregnancy }(n=6)\end{array}$ \\
\hline Age (years, SD) & $33.8(4.6)$ & $33.0(3.1)$ & 0.549 & $34.6(3.5)$ \\
\hline BMI $\left(\mathrm{kg} / \mathrm{m}^{2}, \mathrm{SD}\right)$ & $23.1(3.2)$ & $22.1(2.4)$ & 0.389 & $21.1(2.8)$ \\
\hline Smoking & $2(20)$ & $0(0)$ & 0.119 & $0(0)$ \\
\hline Previously gravid & $1(10)$ & $4(27)$ & 0.745 & $2(33)$ \\
\hline Previous deliveries & $0(0)$ & $3(17)$ & 0.393 & $1(17)$ \\
\hline Previous infertility & $7(70)$ & $11(61)$ & 0.703 & $3(50)$ \\
\hline Previous operations due to endometriosis & $6(60)$ & $3(17)$ & 0.100 & $0(0)$ \\
\hline Type of endometriosis & & & 0.961 & \\
\hline Group A & $2(20)$ & $4(27)$ & & $1(17)$ \\
\hline Group B & $5(50)$ & $8(44)$ & & $4(67)$ \\
\hline Group C & $3(30)$ & $6(33)$ & & $1(17)$ \\
\hline Laparoscopy & $5(50)$ & $10(56)$ & 0.544 & $5(83)$ \\
\hline Bowel resection & $4(40)$ & $8(44)$ & 1.000 & $2(33)$ \\
\hline Hydronephrosis & $2(20)$ & $6(33)$ & 0.669 & $1(17)$ \\
\hline Status of ovaries after operation & & & 0.399 & \\
\hline No procedures & $6(60)$ & $10(56)$ & & $4(67)$ \\
\hline To one ovary & $1(10)$ & $4(22)$ & & $2(33)$ \\
\hline To both ovaries & $0(0)$ & $2(11)$ & & $0(0)$ \\
\hline Frequent procedures & $3(30)$ & $2(11)$ & & $0(09$ \\
\hline Major complications & & & 0.341 & \\
\hline Grade I & $1(10)$ & $0(0)$ & & $0(0)$ \\
\hline Grade II & $5(50)$ & $6(33)$ & & $2(33)$ \\
\hline Grade III & $0(0)$ & $1(6)$ & & $0(0)$ \\
\hline Grade IV & $0(0)$ & $0(0)$ & & $0(0)$ \\
\hline Follow-up time (years, SD) & $5.2(3.3)$ & $5.5(2.4)$ & 0.767 & $4.2(1.6)$ \\
\hline
\end{tabular}

Data are shown as $n(\%)$ unless stated otherwise

in our series as our urologist are not yet so familiar with advanced laparoscopy.

As there is no specific procedure code for ureterolysis, we were unable to retrieve all ureteral shaving operations performed in connection with DIE of the rectovaginal septum. The indications for UNC in our study were moderate or severe hydronephrosis with or without decrease in the kidney function, silent kidney, and reoperation in which ureterolysis could not be performed. Preoperative differentiation between intrinsic and extrinsic ureteral endometriosis is not always easy. Extrinsic type of ureteral endometriosis is more common and endometriosis lesion invades only to the ureteral adventitia or surrounding connective tissue without hydronephrosis. This type of endometriosis can be treated by ureteral shaving but the recurrence rate varies from 20 to $33 \%$ [3]. Intrinsic type of ureteral endometriosis represents around $20 \%$ of cases and lesion infiltrates to the muscular layer of the ureter. This type of endometriosis with moderate or severe hydronephrosis often needs ureteral resection and reanatomosis or reimplantation. It is controversial what kind of operation is needed in case of hydronephroses and diminished renal function [3].
Large endometriotic nodule and severe hydronephrosis are risk factors for adverse outcome and might be indications for ureteral resection [35]. In our study, UNC was chosen as endometriotic lesions were large, situated near the bladder wall, or caused hydronephrosis but most of the lesions were extrinsic by histology. It means that in theory ureterolysis via ureteral shaving could have been performed more often [31, 44]. In the future, we aim to increase the proportion of laparoscopic surgery in UTE as in many other referral centers.

UTE cannot be discussed without taking the other aspects of DIE affecting the symptoms and operations into consideration. As expected, the operations in our study were difficult and concomitant procedures were numerous. Also, the rate of bowel resection was higher (i.e., $40 \%$ ) than in some studies $[6,32,33,39,43]$. However, some of the previous studies have included patients with only isolated bladder endometriosis or cases where only ureteral endometriosis has been operated upon [6, 38]. Moreover, collaboration of different specialists is not commonly reported, even though the purpose is complete resection of all endometriotic lesions in the same operation. In Finland, multidisciplinary approach is 
recommended [31, 43, 45] in contrast to some other countries where gynecologist commonly perform urinary and gastrointestinal surgery on their own $[3,38]$. In our study, a second specialist, either a urologist or a gastrointestinal surgeon, attended the operation in more than $60 \%$ of the cases.

The rate and type of complications was in line with those reported in previous studies $[5,31,33]$. The most typical complication was intraoperative hemorrhage of over $1000 \mathrm{ml}$, but this only occurred during laparotomies. The amount of intraoperative bleeding is rarely reported in other studies. Altogether, $53 \%$ had some problems postoperatively; most of them were minor. However, $9 \%$ of women needed a reoperation for complications: perforation of the ileum after adhesiolysis, ureteral lesion caused by electrocoagulation in connection with bowel resection, rupture of bladder sutures, rupture of fascial sutures, and intra-abdominal abscess. There was no difference in complications needing a re-intervention between laparoscopy or laparotomy. Three bladder leakages were discovered in routine cystography before removal of a bladder catheter and leakage was cured with prolonged use of the catheter. In addition, urine leakage from the bladder to the vagina and rectum 1 day after the removal of a bladder catheter was cured with extended use of a catheter whereas one postoperative hydronephrosis was treated with a ureteral stent.

Ninety-four percent of women attended the follow-up visit, $76 \%$ of them were asymptomatic and only one patient needed temporary self-catheterization after removal of the bladder catheter. Twenty-four percent of women had some problems at $1-2$ months postoperatively but only $4 \%(2 / 50)$ were severe. The long-term follow-up was 5.1 years and two women were lost after moving elsewhere. The recurrence rate of UTE following surgery was $4 \%$, which is comparable with that in previous studies $[6,10,33-35]$. Thus, it has been suggested that recurrences are less common after surgery for UTE than for other forms of endometriosis [10].

Fertility has been studied more widely among DIE than UTE patients. As infertility was affecting over half of our patients preoperatively, we consider that reporting postoperative pregnancy rates is important. Only a few studies have involved assessment of fertility following surgical treatment of UTE and to our knowledge there are no previous studies of pregnancy complications or deliveries. A cohort study of 109 women reported postsurgical fertility after laparoscopic excision of ureteral endometriosis, demonstrating a total of 26 pregnancies in 20 women (56\%), among the 36 women who wished to conceive [35]. In studies concerning fertility after operative treatment of rectovaginal endometriosis, the postoperative pregnancy rate has ranged between 19 and $65 \%$ among all patients $[28-30,46]$, and among patients with a history of infertility, between 10 and $58 \%$ [28, 30, 45, 46]. In our study, the corresponding figures were 64 and $61 \%$. Moreover, live birth rates were 56 and $61 \%$, which is very encouraging. As ART was needed in most cases, these figures might also reflect the development of infertility treatments, as also suggested in connection with a national Danish cohort study [47]. Remarkably, in two cases treatment with donated oocytes was used, although in one of these cases several procedures involving both ovaries were performed.

Analysis of multiple pre- and perioperative factors did not reveal any differences between women who eventually conceived vs. those who did not. This is in contrast to the results of previous studies, in which concurrent adenomyosis or hydronephrosis [35], older woman or high ASRM scores [48], or surgical treatment by means of laparotomy [28, 46] has been associated with lower postoperative pregnancy rates among women with DIE. Unfortunately, we do not have data on the incidence of adenomyosis in our patients. In our study, only one spontaneous pregnancy occurred after laparotomy and five spontaneous pregnancies occurred after laparoscopy.

To our knowledge, no previous study has been carried out to assess the incidence of pregnancy or delivery complications among women who have undergone operation for UTE. A high rate, up to three quarters of all pregnancies and deliveries in our series, were complicated. In a large Swedish registrybased study, all forms of endometriosis were found to be associated with increased risks of preeclampsia, antepartum hemorrhage, and preterm birth as well as an increase in the rate of cesarean delivery [49]. Moreover, rectovaginal endometriosis has been associated with a risk of placenta previa [30]. Thus, our results on the rate of complicated delivery are in line with those concerning endometriosis in general or DIE $[30,49]$, with the exception that the rate of cesarean delivery was even higher. In addition, the majority of these deliveries ended as emergency operations, hemorrhage exceeding $1500 \mathrm{ml}$ occurred in more than half of the cases and intraoperative problems occurred in $80 \%$ of the cesarean deliveries. All these figures are several-fold greater than those reported in connection with cesarean sections overall in Finland [50]. As the number of cesarean deliveries was limited, we did not see a significant correlation between various perioperative factors in the primary operation (such as blood loss) and the risk of emergency or complicated cesarean section. In our series, bladder was opened in all except two patients either due to resection of bladder endometriosis or in connection with UNC procedure. Postoperative adhesions could in theory make cesarean sections more difficult. Hence, according to this study, both pregnancy and delivery complications were common after operative treatment of UTE.

Our study has limitations. In this retrospective case series, the number of patients is small, which is a common problem in connection with this form of endometriosis. Operative skills of our gynecologists may not be as good as in larger laparoscopic centers. However, the retrospective nature of the study does not impair its validity, as we had good access to all follow-up data including the postoperative pregnancies and their outcomes. Also, the follow-up time is one of the longest $[32,33]$. 
In conclusion, with the use of preoperative imaging, planning, and multidisciplinary team work, the complication and recurrence rates of operatively treated UTE are acceptable. Two thirds of the women who wished for pregnancy conceived, but mostly by means of ART. However, pregnancies and deliveries following UTE surgery may carry a risk of complications. Thus, centralizing the overall care of UTE patients to a few referral centers seems justified.

Acknowledgments This study was supported by Helsinki University Central Hospital Research funds.

The authors would like to thank Arja-Riitta Pauna for radiological consultation and Maarit Mentula for her kind advice with the statistics.

Authors' contribution L Saavalainen performed data collection and managing, data analysis, and manuscript writing. O Heikinheimo was responsible for project development, data analysis, and manuscript editing. A Tiitinen was responsible for project development and manuscript editing. P Härkki was responsible for project development, data managing, data analysis, and manuscript editing.

\section{Compliance with ethical standards}

Conflicts of interest The authors declare that they have no conflict of interest.

Informed consent For this kind of electronic data-based study, informed consent is not required in Finland.

Human studies This article does not contain any studies with human participants performed by any of the authors.

\section{References}

1. Maccagnano C, Pellucchi F, Rocchini L, Ghezzi M, Scattoni V, Montorsi F, Rigatti P, Colombo R (2012) Diagnosis and treatment of bladder endometriosis: state of the art. Urol Int 89:249-258. doi: $10.1159 / 000339519$

2. Maccagnano C, Pellucchi F, Rocchini L, Ghezzi M, Scattoni V, Montorsi F, Rigatti P, Colombo R (2013) Ureteral endometriosis: proposal for a diagnostic and therapeutic algorithm with a review of the literature. Urol Int 91:1-9. doi:10.1159/000345140

3. Knabben L, Imboden S, Fellmann B, Nirgianakis K, Kuhn A, Mueller MD (2015) Urinary tract endometriosis in patients with deep infiltrating endometriosis: prevalence, symptoms, management, and proposal for a new clinical classification. Fertil Steril 103:147-152

4. Donnez J, Nisolle M, Squifflet J (2002) Ureteral endometriosis: a complication of rectovaginal endometriotic (adenomyotic) nodules. Fertil Steril 77:32-37. doi:10.1016/S0015-0282(01)02921-1

5. Kjer JJ, Kristensen J, Hartwell D, Jensen MA (2014) Full-thickness endometriosis of the bladder: report of 31 cases. Eur J Obstet Gynecol Reprod Biol 176:31-33. doi:10.1016/j.ejogrb.2014.02.018

6. Antonelli A, Simeone C, Zani D, Sacconi T, Minini G, Canossi E, Cunico S (2006) Clinical aspects and surgical treatment of urinary tract endometriosis: our experience with 31 cases. Eur Urol 49: 1093-1098. doi:10.1016/j.eururo.2006.03.037

7. Bosev D, Nicoll LM, Bhagan L, Lemyre M, Payne CK, Gill H, Nezhat C (2009) Laparoscopic management of ureteral endometriosis: the Stanford University hospital experience with 96 consecutive cases. J Urol 182:2748-2752. doi:10.1016/j.juro. 2009.08.019

8. Roman H, Vassilieff M, Gourcerol G, Savoye G, Leroi AM, Marpeau L, Michot F, Tuech JJ (2011) Surgical management of deep infiltrating endometriosis of the rectum: pleading for a symptom-guided approach. Hum Reprod 26:274-281. doi:10. 1093/humrep/deq332

9. Payá V, Hidalgo-Mora J, Diaz-Garcia C, Pellier A (2011) Surgical treatment of rectovaginal endometriosis with rectal involvement. Gynecol Surg 8:269-277

10. Seracchioli R, Mabrouk M, Montanari G, Manuzzi L, Concetti S, Venturoli S (2010) Conservative laparoscopic management of urinary tract endometriosis (UTE): surgical outcome and long-term follow-up. Fertil Steril 94:856-861. doi:10.1016/j.fertnstert.2009. 04.019

11. Dunselman GAJ, Vermeulen N, Becker C, Calhaz-Jorge C, D'Hooghe T, De Bie B, Heikinheimo O, Horne AW, Kiesel L, Nap A, Prentice A, Saridogan E, Soriano D, Nelen W (2014) ESHRE guideline: management of women with endometriosis. Hum Reprod 29:400-412. doi:10.1093/humrep/det457

12. Gupta S, Agarwall A, Agarwal R, Ricardo Loret de Mola J (2006) Impact of ovarian endometrioma on assisted reproduction outcomes. Reprod Biomed 13:349-360

13. Benaglia L, Pasin R, Somigliana E, Vercellini P, Ragni G, Fedele L (2011) Unoperated ovarian endometriomas and responsiveness to hyperstimulation. Hum Reprod 26:1356-1361. doi:10.1093/ humrep/der097

14. Ruiz-Flores FJ, Garcia-Velasco JA (2012) Is there a benefit for surgery in endometrioma-associated infertility? Curr Opin Obstet Gynecol 24:136-140. doi:10.1097/GCO.0b013e32835175d9

15. Papaleo E, Ottolina J, Vigano P, Brigante C, Marsiglio E, De Michele F, Candiani M (2011) Deep pelvic endometriosis negatively affects ovarian reserve and the number of oocytes retrieved for in vitro fertilization. Acta Obstet Gynecol Scand 90:878-884. doi: 10.1111/j.1600-0412.2011.01161.x

16. Ballester M, Oppenheimer A, d'Argent EM, Touboul C, Antoine J, Nisolle M, Darai E (2012) Deep infiltrating endometriosis is a determinant factor of cumulative pregnancy rate after intracytoplasmic sperm injection/in vitro fertilization cycles in patients with endometriomas. Fertil Steril 97:367-3U2. doi:10.1016/j. fertnstert.2011.11.022

17. Somigliana E, Berlanda N, Benaglia L, Vigano P, Vercellini P, Fedele L (2012) Surgical excision of endometriomas and ovarian reserve: a systematic review on serum antimullerian hormone level modifications. Fertil Steril 98:1531-1538. doi:10.1016/j.fertnstert. 2012.08.009

18. Muzii L, Di Tucci C, Di Feliciantonio M, Marchetti C, Perniola G, PB P (2014) The effect of surgery for endometrioma on ovarian reserve evaluated by antral follicle count: a systematic review and meta-analysis. Hum Reprod 29:2190-2198. doi:10.1093/humrep/ deu199

19. Stepniewska A, Pomini P, Bruni F, Mereu L, Ruffo G, Ceccaroni M, Scioscia M, Guerriero M, Minelli L (2009) Laparoscopic treatment of bowel endometriosis in infertile women. Hum Reprod 24: 1619-1625. doi:10.1093/humrep/dep083

20. Bianchi PHM, Pereira RMA, Zanatta A, Alegretti JR, Motta ELA, Serafini PC (2009) Extensive excision of deep infiltrative endometriosis before in vitro fertilization significantly improves pregnancy rates. J Minim Invasive Gynecol 16:174-180. doi:10.1016/j.jmig. 2008.12.009

21. Douay-Hauser N, Yazbeck C, Walker F, Luton D, Madelenat P, Koskas M (2011) Infertile women with deep and intraperitoneal endometriosis: comparison of fertility outcome according to the extent of surgery. J Minim Invasive Gynecol 18:622-628. doi:10. 1016/j.jmig.2011.06.004 
22. Vercellini P, Pietropaolo G, De Giorgi O, Daguati R, Pasin R, Crosignani PG (2006) Reproductive performance in infertile women with rectovaginal endometriosis: is surgery worthwhile? Obstet Gynecol 195:1303-1310. doi:10.1016/j.ajog.2006.03.068

23. Kondo W, Darai E, Yazbeck C, Panel P, Tamburro S, Dubuisson J, Jardon K, Mage G, Madelenat P, Canis M (2011) Do patients manage to achieve pregnancy after a major complication of deeply infiltrating endometriosis resection? Eur J Obstet Gynecol Reprod Biol 154:196-199. doi:10.1016/j.ejogrb.2010.09.007

24. Berlanda N, Vercellini P, Fedele L (2010) The outcomes of repeat surgery for recurrent symptomatic endometriosis. Curr Opin Obstet Gynecol 22:320-325. doi:10.1097/GCO.0b013e32833bea15

25. Vercellini P, Somigliana E, Daguati R, Barbara G, Abbiati A, Fedele L (2009) The second time around: reproductive performance after repetitive versus primary surgery for endometriosis. Fertil Steril 92: 1253-1255. doi:10.1016/j.fertnstert.2009.04.037

26. Roman H (2015) Colorectal endometriosis and pregnancy wish: why doing primary surgery. Front Biosci 7:83-93

27. Dindo D, Demartines N, Clavien P (2004) Classification of surgical complications - a new proposal with evaluation in a cohort of 6336 patients and results of a survey. Ann Surg 240:205-213. doi:10. 1097/01.sla.0000133083.54934.ae

28. Darai E, Lesieur B, Dubernard G, Rouzier R, Bazot M, Ballester M (2011) Fertility after colorectal resection for endometriosis: results of a prospective study comparing laparoscopy with open surgery. Fertil Steril 95:1903-1908. doi:10.1016/j.fertnstert.2011.02.018

29. Tarjanne S, Heikinheimo O, Mentula M, Harkki P (2015) Complications and long-term follow-up on colorectal resections in the treatment of deep infiltrating endometriosis extending to bowel wall. Acta Obstet Gynecol Scand 94:72-79. doi:10.1111/ aogs. 12515

30. Vercellini P, Parazzini F, Pietropaolo G, Cipriani S, Frattaruolo MP, Fedele L (2012) Pregnancy outcome in women with peritoneal, ovarian and rectovaginal endometriosis: a retrospective cohort study. BJOP 119:1538-1543. doi:10.1111/j.1471-0528.2012. 03466.x

31. Rozsnyai F, Roman H, Resch B, Dugardin F, Berrocal J, Descargues G, Schmied R, Boukerrou M, Marpeau L, CIRENDO Study Grp (2011) Outcomes of surgical management of deep infiltrating endometriosis of the ureter and urinary bladder. JSLS 15: 439-447. doi:10.4293/108680811X13176785203798

32. Schonman R, Dotan Z, Weintraub AY, Bibi G, Eisenberg VH, Seidman DS, Goldenberg M, Soriano D (2013) Deep endometriosis inflicting the bladder: long-term outcomes of surgical management. Arch Gynecol Obstet 288:1323-1328. doi:10.1007/s00404-0132917-6

33. Chapron C, Bourret A, Chopin N, Dousset B, Leconte M, Amsellem-Ouazana D, de Ziegler D, Borghese B (2010) Surgery for bladder endometriosis: long-term results and concomitant management of associated posterior deep lesions. Hum Reprod 25:884 889. doi:10.1093/humrep/deq017

34. Fedele L, Bianchi SF, Zanconato G, Bergamini V, Berlanda N, Carmignani L (2005) Long-term follow-up after conservative surgery for bladder endometriosis. Fertil Steril 83:1729-1733. doi:10. 1016/j.fertnstert.2004.12.047

35. Uccella S, Cromi A, Casarin J, Bogani G, Pinelli C, Serati M, Ghezzi F (2014) Laparoscopy for ureteral endometriosis: surgical details, long-term follow-up, and fertility outcomes. Fertil Steril 102:160- +. doi:10.1016/j.fertnstert.2014.03.055

36. Exacoustos C, Malzoni M, Di Giovanni A, Lazzeri L, Tosti C, Petraglia F, Zupi E (2014) Ultrasound mapping system for the surgical management of deep infiltrating endometriosis. Fertil Steril 102:143- +. doi:10.1016/j.fertnstert.2014. 03.043

37. Ghezzi F, Cromi A, Bergamini V, Serati M, Sacco A, Mueller MD (2006) Outcome of laparoscopic ureterolysis for ureteral endometriosis. Fertil Steril 86:418-422. doi:10. 1016/j.fertnstert.2005.12.071

38. Frenna V, Santos L, Ohana E, Bailey C, Wattiez A (2007) Laparoscopic management of ureteral endometriosis: our experience. J Minim Invasive Gynecol 14:169-171. doi:10.1016/j.jmig. 2006.09.009

39. Kovoor E, Nassif J, Miranda-Mendoza I, Wattiez A (2010) Endometriosis of bladder: outcomes after laparoscopic surgery. J Minim Invasive Gynecol 17:600-604. doi:10.1016/j. jmig.2010.05.008

40. Nezhat $\mathrm{C}$, Nezhat F, Nezhat $\mathrm{CH}$, Nasserbakht F, Rosati M, Seidman DS (1996) Urinary tract endometriosis treated by laparoscopy. Fertil Steril 66:920-924

41. Mereu L, Gagliardi ML, Clarizia R, Mainardi P, Landi S, Minelli L (2010) Laparoscopic management of ureteral endometriosis in case of moderate-severe hydroureteronephrosis. Fertil Steril 93:46-51. doi:10.1016/j.fertnstert.2008.09.076

42. Stepniewska A, Grosso G, Molon A, Caleffi G, Perin E, Scioscia M, Mainardi P, Minelli L (2011) Ureteral endometriosis: clinical and radiological follow-up after laparoscopic ureterocystoneostomy. Hum Reprod 26:112-116. doi:10.1093/ humrep/deq293

43. Schonman R, Dotan Z, Weintraub AY, Goldenberg M, Seidman DS, Schiff E, Soriano D (2013) Long-term follow-up after ureteral reimplantation in patients with severe deep infiltrating endometriosis. Eur J Obstet Gynecol Reprod Biol 171:146-149. doi:10.1016/ j.ejogrb.2013.08.027

44. Miranda-Mendoza I, Kovoor E, Nassif J, Ferreira H, Wattiez A (2012) Laparoscopic surgery for severe ureteric endometriosis. Eur J Obstet Gynecol Reprod Biol 165:275-279. doi:10.1016/j. ejogrb.2012.07.002

45. Stepniewska A, Pomini P, Scioscia M, Mereu L, Ruffo G, Minelli L (2010) Fertility and clinical outcome after bowel resection in infertile women with endometriosis. Reprod BioMed Online 20:602609. doi:10.1016/j.rbmo.2009.12.029

46. Ferrero S, Anserini P, Abbamonte LH, Ragni N, Camerini G, Remorgida V (2009) Fertility after bowel resection for endometriosis. Fertil Steril 92:41-46. doi:10.1016/j.fertnstert.2008.04.070

47. Hansen MVH, Dalsgaard T, Hartwell D, Skovlund CW, Lidegaard O (2014) Reproductive prognosis in endometriosis. A national cohort study. Acta Obstet Gynecol Scand 93:483-489. doi:10.1111/aogs.12373

48. Darai E, Carbonnel M, Dubernard G, Lavoue V, Coutant C, Bazot M, Ballester M (2010) Determinant factors of fertility outcomes after laparoscopic colorectal resection for endometriosis. Eur J Obstet Gynecol Reprod Biol 149:210-214. doi:10.1016/j.ejogrb. 2009.12.032

49. Stephansson O, Kieler H, Granath F, Falconer H (2009) Endometriosis, assisted reproduction technology, and risk of adverse pregnancy outcome. Hum Reprod 24:2341-2347. doi:10.1093/humrep/dep186

50. Pallasmaa N, Ekblad U, Aitokallio-Tallberg A, Uotila J, Raudaskoski T, Ulander V, Hurme S (2010) Cesarean delivery in Finland: maternal complications and obstetric risk factors. Acta Obstet Gynecol Scand 89:896-902. doi:10.3109/00016349.2010. 487893 